\title{
Performace Evaluation \& Life Cycle Costs In Rewound Induction Motors Used In Spinning Units
}

\author{
Ramandip Singh, Dr. S.K.Bath, Varinder Goyal \\ Research Scholar, Department of Electrical Engineering, P.T.U G.Z.S.Campus Bathinda \\ H.O.D Department of Electrical Engg. PTUGZS Campus, Bathinda \\ A.P, Department of Electrical Engg. G.T.B.K.I.E.T CHHAPIANWALI, MALOUT
}

\begin{abstract}
Induction motors being the major energy consumer in the plant offer opportunities of energy saving. In the spinning unit many induction motors are in-house rewound. This paper reports the analysis done on the rewound induction motors to determine its efficiency and life cycle cost comparison. Practical comparisons between rewound motors and the new motors are shown.
\end{abstract}

Keywords: Rewound induction motor, energy loss, efficiency, life cycle cost, spinning unit.

\section{INTRODUCTION}

The electrical motors consume large amount of electrical energy. Nearly $80-85 \%$ of the load in a spinning unit is on account of induction motors [1]. In these industries a common prevalent practice is to repair and rewind a faulty motor, instead of replacing it with a new one. The efficiency of the motor decreases after it is rewound. This short term capital saving method thus may have a huge long term loss.

\section{PROBLEM DEFINITION}

The rewound induction motors in textile plant under study are to be analysis for different types of losses in order to get their overall efficiency. The efficiencies of all these motors are then to be compared with the rated and actual efficiencies of new motors taking replacement as one of the options. Recommendations for replacement of rewound motors are to be made accordingly.

\section{METHOD}

Many in-house rewound induction motors are identified in a major textile plant after several visits. Working condition of each in-house rewound induction motor is examined. All the parameters of the rewound induction motors are identified and recorded through different means. All the parameters are divided into three different types i.e. rated, measured and calculated. Different instruments are used to measure the measurable parameters that lead to determination of its efficiency [2]. The parameters and respective instruments used in this exercise are listed in the Table 1.

Table 1

Parameters and Instruments Used

\begin{tabular}{ll}
\hline Parameter & Instrument \\
\hline $\begin{array}{l}\text { Speed } \\
\text { Current }\end{array}$ & Tachometer \\
Voltage & Clamp-on-transducer \\
$\begin{array}{l}\text { Input power } \\
\text { Winding } \\
\text { temperature } \\
\text { Winding resistance }\end{array}$ & Power analyzer \\
& Power analyzer \\
\hline
\end{tabular}




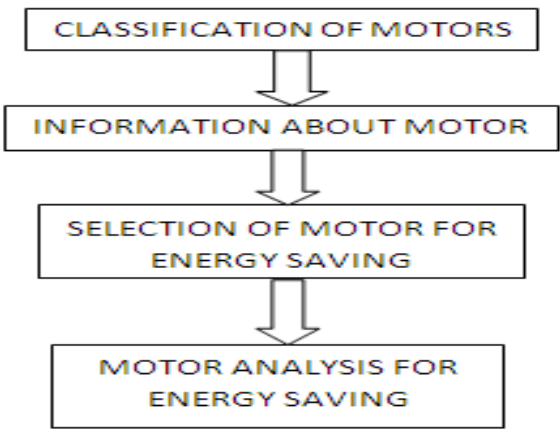

Figure 1: Procedure to Analysis of the Motor

\section{RESULTS AND DISCUSSION}

In the plant, the saving in electrical energy is found by analyzing some of the in-house rewound induction motors and looking for alternative options to increase the efficiency of the motors. Sample parameters of one of the in-house rewound induction motor are given in Table 2 after applying the relevant formulae [3, 4].

Table 2 Rated and Measured Parameters of Rewound Induction Motor

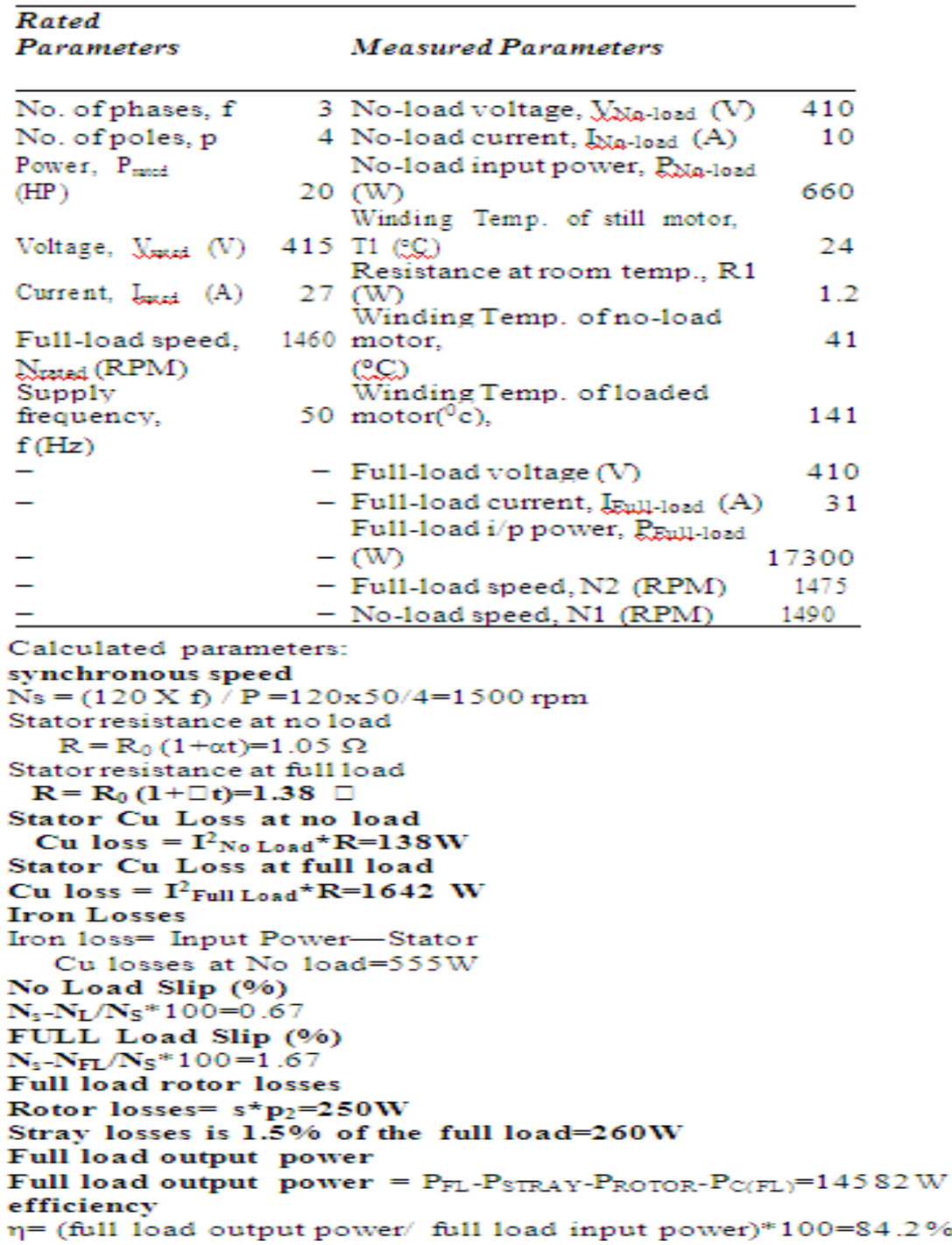

Determined efficiency of an analyzed in-house rewound induction motor $=84.2 \%$

Similarly, determined efficiency of an analyzed new motor $=93.25 \%$

Analysis done on few rewound motors including described above is shown below in the form of graphs: 


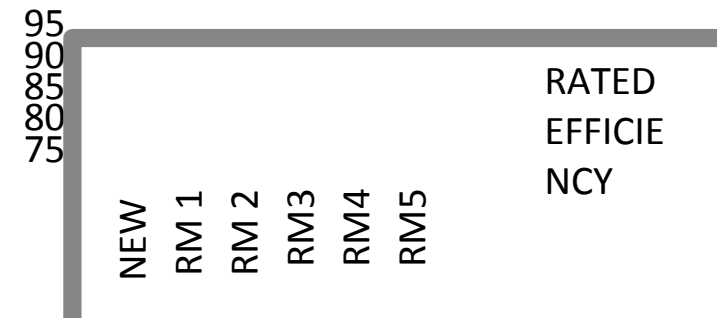

Figure 2: 15HP Motor Analysis

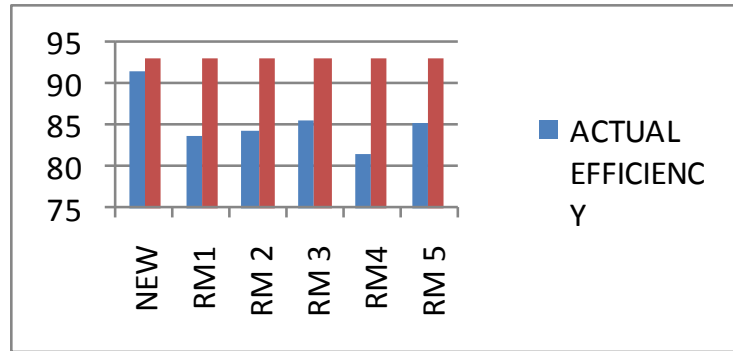

Figure 3: 20HP Motor Analysis

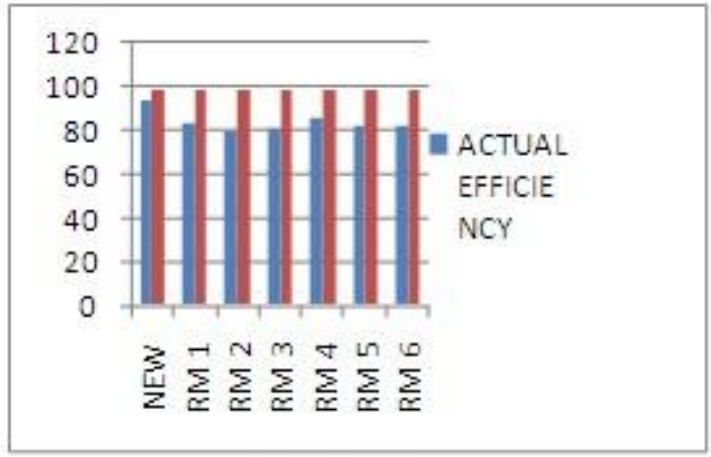

Figure- 4: 50HPMotor Analysis

Figure 2-4 show the efficiencies of new and rewound motors thus rewound motors has low efficiency and more losses. [5].

\section{Life Cycle Cost of Induction Motor}

The majority of motors in the field are induction motors. The industry is becoming increasingly concerned about the ability of electric motors to ride through power system disturbances. There may be various reasons for the desire of testing induction motors in the field, such as the consideration of exchanging out of date or worn motors with new, or checking the efficiencies after rewinding.

\section{Life Cycle Cost Comparison of Induction Motor}

Indian industry is currently feeling a squeeze on profits due to the rapid rise in power costs. It is no longer practical to consider the monthly power bill as a fixed base cost that cannot be controlled. Power costs have been raising faster than both material and producer good prices. During the 2000's they were increasing at approximately the same rate, and it was generally possible to pass any power increase along to the customer in the form of a price increase. After the energy crunch, power rates increased much faster than the prices for products, so any portion of power posts that could not be passed along came directly out of profits. Since motors account for over 90 percent of power used by industry, they have always had an impact on operating costs. In today's economy, it is more important than ever to keep the cost of motor losses under control. So for Life cycle cost comparison method first of all we have to calculate the rated speed, Efficiencies, Prices of new and rewind motors. 
Life-Cycle Cost (LCC)

$\mathrm{LCC}=\mathrm{PP}+\mathrm{EF} \times \mathrm{KW}_{\mathrm{e}}$ here LCC $=$ Life Cycle Cost

$\mathrm{PP}=$ Motor Purchase price

$\mathrm{EF}=$ Evaluation Factor

$\mathrm{KW}_{\mathrm{e}}=$ Evaluated loss.

Table-3 Life cycle cost comparison of different motors

\begin{tabular}{|c|c|c|c|c|c|c|}
\hline Motor type and Rating & \multicolumn{6}{|c|}{ Life Cycle Cost of One Year(Rupee) } \\
\hline & New & R.M 1 & R.M 2 & R.M 3 & R.M 4 & R.M 5 \\
\hline 15HP & 237694 & 299950 & 319241 & 280328 & 429935 & 313857 \\
\hline $20 \mathrm{HP}$ & 316342 & $\mathbf{5 0 4 7 2 0}$ & 488797 & 449082 & 568183 & 461160 \\
\hline 50HP & 555819 & 1153253 & 1339678 & 1539806 & 992819 & 1198337 \\
\hline
\end{tabular}

\section{CONCLUSION AND FUTURE SCOPE}

In spinning unit many induction motors are reused after rebounding. In the present study, performance evaluation and efficiency analysis of rewound motors has been done and the results are compared with those of new motors. Also life cycle costs of new and rewound motors have been evaluated and compared. From the study, it is found that rewound motor consumes 1.5 times to 3 times more energy than new motor Based on the study recommendation has been suggested. Scope of power saving exists in improving the power-factor. A future study on power factor analysis and improvement in thus suggested.

\section{REFERENCE:}

[1]. Cummings Paul G, Bowers W. D, "Induction Motor Efficiency Test Methods", IEEE Transactions On Industry Applications, VOL. IA-17, No. 3, May/June 1981,PP 253-272

[2]. Aquila A. Dell', Salvatore L., and Savino M. "A New Test Method for Determination of Induction Motor Efficiency IEEE Power Engineering Review, October 1984, PP 48-49

[3]. Montgomery David C, "The Motor Rewind Issue-A New Look", IEEE Transactions on Industry Applications, VOL. LA-20, NO. 5, September/October 1984, PP 1330-1336

[4]. Schwartz Thomas F., Discussion of "The Motor Rewind Issue- A New Look", IEEE Transactions on Industry Applications. VOL IA-21, NO.2.. March/April 1985, PP 356

[5]. Richter Eike, MillerTimothy J.E, Neumann Thomas W, Hudson Thomas L, "The Ferrite Permanent Magnet AC Motor-A Technical and Economical Assessment", IEEE Transactions on Industry Applications, VOL. IA-21, NO. 4, May/June 1985, PP 644-650

[6]. Binns D.F., "Comparative costs of energy losses in induction Motors",Electric Power Application IEEE Proceedings, Vol. 134, Pt. B, No. 4, July 1987,PP 177-182

[7]. Medarametla J. B, Cox M. D, Baghzouz Y, "Calculations And Measurements Of The Unity Plus ThreePhase Induction Motor", IEEE Transactions on Energy Conversion, Vol. 7, No 4, December 1992,PP732-738

[8]. Grantham C, McKinnon D.J, “A Novel Method for Load Testing and Efficiency Measurement of Three-phase Induction Motors", Electric Machines and Drives Conference IEEE, IEMDC'03. IEEE International, 2003, PP769-775

[9]. Hamer Paul S, Lowe Debra M, Wallace Stanley E, "Energy-Efficient Induction Motors Performance Characteristics and Life-Cycle Cost Comparisons for Centrifugal Loads", IEEE Transactions on Industry Applications, VOL. 33, NO. 5, September/October 1997, PP 1312-1320

[10]. Hsu J. S, Kueck J. D, Olszewski M, Casada D. A, Otaduy P. J, Tolbert L. M, "Comparison of Induction Motor Field Efficiency Evaluation Methods", Industry Applications Conference, 1996, Thirty First IAS Annual Meeting ,IAS'96.,Conference Record of the 1996 IEEE, vol. 1, PP 703-712 